\title{
PEPS: An Introduction to Engineering Design for Secondary School Teachers
}

\author{
Patrick Little and Lori Bassman \\ Harvey Mudd College, Claremont, CA
}

\begin{abstract}
Each summer the Engineering Department at Harvey Mudd College (HMC) conducts Partners in Engineering Problem Solving (PEPS), a workshop for secondary school math and science teachers with the aim of introducing them to the design methodologies used in HMC's freshman engineering course. That course, Introduction to Engineering Design, and the workshop use studio methods to teach design methodologies, team formation and dynamics, and project management. The five-day workshop brings together teachers from around the United States and immerses them into a hands-on design problem. The ultimate goal of the workshop is to empower educators to develop and apply methods of problem solving and engineering design to open-ended problems in their classrooms. Most of the attendees are selected from schools serving populations traditionally underrepresented in engineering. In addition to exposing the teachers to engineering design methods, the workshop serves to facilitate discussions on how best to attract students into engineering and the sciences.

PEPS was originally developed as an extension of a program at Dartmouth College, and has been significantly modified to use the particular strengths available at HMC. An interesting aspect of PEPS has been its use by HMC faculty to conduct pedagogical experiments that have been later implemented in the college classroom. The workshop has been examined using formal assessment techniques and instruments and appears to be realizing its stated goals.
\end{abstract}

\section{Introduction}

For the past four years, Harvey Mudd College (HMC) has hosted a workshop for secondary school teachers of math and science. The primary purpose of the workshop is to offer the teachers an introduction to elements of engineering design in a way that will encourage them to incorporate engineering design projects into the high school curriculum. The workshop, Partners in Engineering Problem Solving (PEPS), begins with a hands-on design exercise, and culminates with the participants preparing and presenting lesson plans to be used at their own schools. The workshop utilizes materials from HMC's first course in engineering, Introduction to Engineering Design (known as "E4") [1], and is taught in a studio mode [2]. This paper presents some background material on PEPS, including the program's goals, the current structure of PEPS, a discussion of the assessment procedures used, and some reflections on future directions. 


\section{Background and Goals of PEPS}

PEPS originated from a Dartmouth College program of the same name. In 1997, Dartmouth changed its program from a workshop for high school teachers to a workshop aimed at establishing "daughter sites" at colleges and universities around the country. A team of two HMC professors and a high school teacher from Southern California were among the attendees. A decision was made to establish a successor program at HMC, with several modifications. These were a shortening of the workshop from nine days to three, a more explicit discussion of formal design methods, and offering of stipends to attendees as a way of demonstrating an appreciation of the value of their time.

From the outset, PEPS organizers at HMC and the HMC administration made a conscious effort to establish clearly defined goals for the program. In addition to simple good management, this was a reflection of a heightened awareness of the importance of assessment in engineering education and in sponsored programs. The general goals for PEPS were to:

- Increase teacher skills/tools

- Increase learning opportunities and skills for students

- Improve quality of science, math and technology (SMT) education environment

- Achieve benefits directly for Harvey Mudd College.

Each of these general goals was expanded into specific objectives. In the area of increased or improved teacher skills, the objectives were to:

- Improve quality of SMT courses in secondary schools that participated in the program

- Increase number of teachers with engineering design knowledge

- Increase awareness of the nature/limits of science

- Raise standards to which students hold themselves (i.e., encourage peer evaluation as an alternative to teacher-based grading)

- Encourage and support implementation of results at the local level after the fact

The goal of increasing student learning opportunities and skills was translated into the following objectives:

- Provide a framework for student decision making and problem solving

- Increase number of students exposed to engineering problem solving and engineering design processes

- Offer another avenue for active learning

- Expand use of groups and teams in classrooms

- Increase awareness by students of group dynamics

- Improve students' understanding of the roles and activities of engineers and scientists

- Enhance students' awareness of the nature/limits of science

For general improvement in SMT education outcomes, the objectives were focused on populations underrepresented in engineering. The objectives in this area were: 
- Increase number of engineering students from underrepresented minorities and women

- Integrate SMT in the high school curriculum and activities

- Integrate school projects with communities

Finally, HMC had certain institutional goals that were incorporated into the PEPS program. These were:

- Enhance HMC recruitment of students from underrepresented groups

- Increase number and quality of applicants to HMC

- Get HMC professors and students into K-12 classrooms with underrepresented students in order to increase faculty and student awareness of prospective student needs.

These goals served to guide the PEPS team in designing and conducting the workshop. In addition, based on results from assessment instruments, the workshop evolved over a period of several years.

The first workshop was held in July of 1998. Eighteen teachers attended, and a project to supply water to an athletic field was used as the design exercise. Based on feedback from the attendees, the workshop was extended from three days to four the following year, when 13 teachers attended. In 2000, twenty-four teachers attended, and the workshop was extended to five days, with the first three devoted to the hands on project and the final two days to implementation issues and development of lesson plans. Financial support for the 1998 through 2000 workshops was provided by Boeing and the National Science Foundation.

\section{Current Implementation of PEPS}

In addition to the continuing funding sources cited above, in 2001 a grant from the Engineering Information Foundation allowed expansion of the workshop with a new focus on educators from girls' high schools. An important addition to the workshop was discussion of teaching methods and approaches that might specifically encourage participation in SMT by young women. There were twenty-eight participants at the 2001 workshop, with eight coming from girls' schools. The selection of these participants and activities in which they were engaged for the PEPS workshops are detailed below. It is the intent of the PEPS teaching team to build on these methods for the upcoming 2002 workshop.

\section{Attendees}

The teachers who participate in PEPS come from schools that fall into one or more of the following categories: 1) schools with significant African American, Native American and/or Latino populations; 2) schools that emphasize science, math and technology in their curricula; and 3) girls' schools. All have a demonstrated interest in improved teaching of science, mathematics and technology. With a mix of participants from communities local to HMC (Los Angeles area) and participants from across the country, the workshop has a geographical balance that allows for several types of networking among teachers when they return to their schools. 
Recruitment of the attendees primarily is done by letters of invitation sent to school principals and math and science department heads. In 2001, a posting was also placed on email lists of AP physics and chemistry teachers. In this way a diverse audience of enthusiastic teachers can be reached. In both cases, invitations indicate that groups of two to four teachers are given preference, since implementation of the activities proposed in PEPS is believed to be more successful when supported by multiple teachers in a school. Mixed groups of math and science teachers are especially welcomed.

\section{Teaching Team}

The teaching team, like the attendees, represents a variety of backgrounds and expertise. Each year, two or more HMC engineering faculty members (instructors of E4, Introduction to Engineering Design) have been joined by one or more high school teachers as instructors for the program. The original high school teachers on the team were participants at the Dartmouth program, but now several previous PEPS attendees who have implemented the workshop methodologies in their own classrooms are invited to join the teaching team. Each year an effort is made to expand the teaching team with the hope that eventually workshops could be held at multiple sites each summer.

\section{Workshop Activities}

Participants experience a busy five-day schedule, the most recent example of which is shown in Figure 1. Throughout the workshop, the structure and content of activities are aimed toward building an awareness of team dynamics and engaging participants in active learning.

The workshop has two major sections: Engineering Problem Solving/Design (Monday morning through Wednesday morning) and Lesson Plan Development (Wednesday afternoon through Friday). The first is led primarily by HMC engineering faculty and the second by the high school teachers on the teaching team.

\section{Introductory Activities}

As many participants and members of the teaching team are not from the Los Angeles area, they arrive Sunday night and stay in an HMC dormitory. Local participants are encouraged to stay in the dormitory as well. Intentionally, participants are placed in suites with teachers from other schools in order to begin building an interactive team environment right away. During meals, starting on Sunday night, they are encouraged to sit with people they do not yet know.

Workshop registration begins on Monday morning. At that time, teachers are provided with a notebook of materials, which includes the text [3], a monograph by the teaching team on the design process, example materials developed by the high school teachers on the teaching team, and materials on Harvey Mudd and the Claremont Colleges. The first formal activity is team formation. The groups are preset by the teaching team based on the attendee information forms received before the workshop. Teachers from the geographical region (but different schools) are intentionally grouped to initiate contacts that might produce future supporting relationships. Most teachers are placed with at least one teammate having similar disciplinary interests. 
Figure 1: PEPS schedule for 2001

\begin{tabular}{|c|c|c|c|c|}
\hline $\begin{array}{l}\text { Monday, } \\
\text { July 23, } 2001\end{array}$ & $\begin{array}{l}\text { Tuesday, } \\
\text { July 24, } 2001\end{array}$ & $\begin{array}{l}\text { Wednesday, } \\
\text { July } 25,2001\end{array}$ & $\begin{array}{l}\text { Thursday, } \\
\text { July } 26,2001\end{array}$ & $\begin{array}{l}\text { Friday, } \\
\text { July } 27,2001\end{array}$ \\
\hline 9:00 - 9:30 & $9: 00-9: 45$ & $8: 30-9: 45$ & $9: 00-10: 00$ & $9: 00-11: 30$ \\
\hline $\begin{array}{l}\text { Registration } \\
9: 30-10: 00\end{array}$ & $\begin{array}{l}\text { Review } \\
\text { assignments }\end{array}$ & $\begin{array}{l}\text { Prepare } \\
\text { Presentations }\end{array}$ & $\begin{array}{l}\text { Work on } \\
\text { implementation } \\
\text { lesson plan }\end{array}$ & $\begin{array}{l}\text { Lesson plan } \\
\text { presentations }\end{array}$ \\
\hline Team formation & $\begin{array}{l}10: 00-11: 45 \\
\text { Generating }\end{array}$ & $\begin{array}{l}\text { 10:00 - 12:00 } \\
\text { Present Results }\end{array}$ & $10: 00-11: 00$ & $\begin{array}{l}\text { 11:30 - 12:00 } \\
\text { Workshop }\end{array}$ \\
\hline $\begin{array}{l}\text { 10:00 - 10:30 } \\
\text { A design }\end{array}$ & alternatives & $12: 15-1: 15$ & $\begin{array}{l}\text { Group/team } \\
\text { dynamics }\end{array}$ & assessment \\
\hline roadmap & $\begin{array}{l}\text { 11:45 - 1:00 } \\
\text { Lunch }\end{array}$ & Lunch - Picnic & discussion & $\begin{array}{l}\text { 12:00 - 1:00 } \\
\text { Lunch }\end{array}$ \\
\hline $10: 30-11: 00$ & & $1: 15-3: 00$ & $11: 00-12: 00$ & \\
\hline $\begin{array}{l}\text { Clarifying the } \\
\text { problem } \\
\text { statement }\end{array}$ & $\begin{array}{l}\text { 1:00 - 2:30 } \\
\text { Selecting an } \\
\text { alternative }\end{array}$ & Open Time & $\begin{array}{l}\text { HS Students who } \\
\text { have worked on } \\
\text { PEPS projects }\end{array}$ & $\begin{array}{l}\text { 1:00 - 2:00 } \\
\text { Follow-up } \\
\text { planning }\end{array}$ \\
\hline $11: 00-11: 45$ & $2: 30-3: 30$ & 3:00 - 4:00 & $12: 00-1: 00$ & END OF PEPS \\
\hline Research & $\begin{array}{l}\text { Defining the } \\
\text { crucial }\end{array}$ & $\begin{array}{l}\text { Women in } \\
\text { engineering }\end{array}$ & Lunch & 2001 \\
\hline $11: 45-1: 00$ & experiment & & $1: 00-3: 00$ & \\
\hline Lunch & 3:30 - 7:30 & $\begin{array}{l}\text { 4:00 - 5:00 } \\
\text { Implementation }\end{array}$ & $\begin{array}{l}\text { Work on } \\
\text { implementation }\end{array}$ & \\
\hline $\begin{array}{l}\text { 1:00 - 2:00 } \\
\text { Research }\end{array}$ & $\begin{array}{l}\text { Build/test } \\
\text { prototype }\end{array}$ & $\begin{array}{l}\text { of Engineering } \\
\text { Design at the }\end{array}$ & lesson plan & \\
\hline continues & $5: 30-6: 30$ & high school level & $\begin{array}{l}\text { 3:00 - 4:00 } \\
\text { Tools for }\end{array}$ & \\
\hline $\begin{array}{l}\text { 2:00 - 3:30 } \\
\text { Objectives and } \\
\text { constraints }\end{array}$ & $\begin{array}{l}\text { Dinner } \\
\text { 7:30 - 8:00 } \\
\text { Presentation }\end{array}$ & $\begin{array}{l}\text { 5:00 - 5:30 } \\
\text { Implementation } \\
\text { group formation }\end{array}$ & $\begin{array}{l}\text { Engineering } \\
\text { Design suitable } \\
\text { for these projects }\end{array}$ & \\
\hline $\begin{array}{l}\text { 3:30 - 5:00 } \\
\text { Functions }\end{array}$ & expectations & $\begin{array}{l}\text { 5:30 - 6:30 } \\
\text { Dinner }\end{array}$ & $\begin{array}{l}\text { 4:00 - 5:00 } \\
\text { Presentation }\end{array}$ & \\
\hline $\begin{array}{l}\text { 5:30 - 7:00 } \\
\text { Dinner }\end{array}$ & $\begin{array}{l}8: 00 \text { - ???? } \\
\text { Additional } \\
\text { build/test time, } \\
\text { as needed }\end{array}$ & & $\begin{array}{l}\text { expectations and } \\
\text { work on } \\
\text { presentations }\end{array}$ & \\
\hline $\begin{array}{l}\text { 7:00 - 8:30 } \\
\text { Documenting } \\
\text { today's work, } \\
\text { planning } \\
\text { tomorrow's work }\end{array}$ & & & $\begin{array}{l}\text { 5:30 - 6:30 } \\
\text { Dinner }\end{array}$ & \\
\hline
\end{tabular}


The first half of the workshop is held in the same studio classroom used for E4. In both the undergraduate course and the workshop, the first task of each team is to organize a workspace by arranging furniture, wall coverings and rugs. The hope is that this activity increases ownership of the workspace and creates team identity [2]. It also serves as an easy icebreaker for the teams.

Engineering Design Problem

In keeping with the pedagogical methods used in HMC's Introduction to Engineering Design [2], as well as to suggest to the participants how they might use active learning in their classrooms, no formal lectures are given during PEPS. While participants might come to intellectually understand the engineering design methodology from lectures or books, the best way for them to truly take ownership of the process is to present them with an opportunity to return to the experience of being students. With no prior introduction, the problem statement in Figure 2 is distributed to the teams, and participants are returned to states of uncertainty, and maybe some anxiety, about learning new material. Guidance from the teaching team is provided when participants request it, but not before.

Although specific topics are listed during the day on Monday in Figure 1, this schedule is only a rough guide; all instruction is prompted by attendees' inquiries. As participants begin to understand that they are to drive their own learning and to pose pertinent questions, the first is often, "Do we have to build a clock?" With the initial realizations that engineering problems do not come nicely packaged, and that the "client" may not always have the clearest idea of the essential problem to be solved, the participants begin their experience of the engineering design process.

By mid-afternoon on Monday there have been short discussions on the vocabulary of design (problem statements, objectives, constraints and functions). Through interactions with the teaching team and by use of the provided text and monograph, attendees are able in one day to gain an understanding of the design vocabulary and tools at a level suitable for introduction to their high school students. Naturally, most teams begin brainstorming ideas for their solutions on Monday as well. It is important that the initial stages of the design process not be overshadowed by the fun of tinkering, and so the materials for prototype construction are not provided right away. Also on Monday, teams are asked to use library and web resources to research possible solutions. For instance, for the problem posed in Figure 2, teams often discover methods for making water clocks, information on search-and-rescue procedures, and survival strategies (although when they ask, they are told that "other castaways" in the group are building rafts, collecting extra food, etc. - their job is to make best use of the large number of flares). The participants, as well as their own students, should be encouraged to use correct citation formats, especially for web references.

Tuesday morning the teams are expected to generate alternatives and decide on a process for selecting among them. Again, selection schemes appropriate to high school students are covered in response to attendee questions. At this time, there is also the beginning of discussion of ways that such an exercise might be brought into high school classrooms. For instance, topics from math and science curricula may be taught via experiments introduced to inform choices among alternatives. By midday, the prototype construction materials (PVC pipe, wood, string, assorted 
Background: You and a group of fellow travelers (teachers returning from yet another tropical cruise, courtesy of your generous school board) have, sadly, been shipwrecked on a deserted island. As the boat sank, you fled for your lives and have only items found on the island, including some bamboo, vines, coconut shells, sand, and rocks. You also have a flashlight that one of the survivors carried in her pocket. There is fresh water running from a waterfall. Emergency food supplies, which will last for three weeks, have floated ashore along with a supply of flares and a flare gun. A small section of the boat appears to have run aground near the shore, and you will have access to it at low tide. The former marine in your group has successfully developed accommodations in the night, although you didn't sleep that well.

Problem Statement: One member of your group remembers a television docudrama on survival on deserted islands, in which it was suggested that you should determine the number of signal flares and the duration of the food supply and set of flares at evenly spaced intervals for as long as the food lasts. In this case, you have enough flares to set one off every 15 minutes. Unfortunately, no clocks or watches survived the shipwreck. As the teachers with the most engineering exposure, you have been asked by the group to design a clock that will set off an audible alarm every 15 minutes.

Team assignment:

(1) Clarify and revise the problem statement to address any biases, errors, or implied solutions (Tuesday $9 \mathrm{am}$ )

(2) A laptop with a wireless modem, a web browser, and a card catalog CD survived with just enough power and capability to allow you to conduct research on possible solutions. Find at least four unique and usable references per person regarding the problem and/or prior solutions. No more than two references per person can be web-based. (It will be necessary for the team to meet and compare references, since no duplicates within a team are allowed.) Construct a bibliography so that future castaways could find and refer to the material. (Tuesday noon)

(3) Determine and document the objectives and constraints associated with this design project (Tuesday $9 \mathrm{am}$ ).

(4) Determine and document the functions that the device must perform (Tuesday 9 am).

(5) Develop some alternative ways to realize those functions (Tuesday noon).

(6) Describe at least two independent, functionally complete design alternatives (Tuesday $3 \mathrm{pm}$ ).

(7) Describe a method for selecting among the alternatives, including an appropriate experiment that demonstrates the efficacy of the design (Tuesday $3 \mathrm{pm}$ ).

(8) Build a working prototype or proof of concept for your selected design, and conduct your experiment (Wednesday $9 \mathrm{am}$ ).

(9) Prepare and present your results to the other castaways (Wednesday 10am).

hardware, etc.) "wash ashore" and building begins. A three-foot high waterfall is constructed in a laboratory for teams' use. At this stage, the members of the teaching team interact with teams individually, challenging their design decisions, questioning how they plan to calibrate their devices, and joining in the victories of successful prototype tests. A task that seemed quite daunting to many attendees on Monday morning produces an especially rewarding experience upon completion.

Because the participants have walked through the design process themselves, they are able to understand the relationship between the timing of introduction of intellectual tools and their own 
creativity. This is helpful for their task in the second half of the workshop, designing an engineering exercise for their own students. Further, because they have been required to work in teams with strangers, they are made very aware of the roles they and others have played in the group dynamic. No doubt all of these teachers are aware of the vocabulary of group dynamics, but with the immediacy of this team experience, their discussions of team building and leadership in the second half of the workshop are given added authenticity.

The final part of the project is a presentation of results to the group as a whole. In ten-minute presentations, the teams must demonstrate the functioning of their prototypes and describe the process by which they have identified the proper design space, generated alternatives, and selected among them. While these presentations are enjoyable during the workshop, participants understand that they will serve a more important purpose for their high school students. As discussed in the following section, evaluation by instructors, peers, and outside observers is a key component of these projects.

One of the interesting phenomena that attendees often comment on is their "return" to studentlike behaviors and attitudes. The presentations seem to particularly elicit this. Members of the HMC faculty and administration who are on campus during the PEPS workshop are invited to attend the presentation and subsequent lunch. Many of the PEPS attendees seem far more nervous about presenting their results to this audience than might be expected of professional educators. The teaching team believes that placing the attendees in this situation is beneficial in terms of reminding them of what their students experience.

\section{Development of Lesson Plans}

Feedback from the first PEPS workshops showed that the chances of implementation by the participants are not good unless time at the workshop is devoted to developing a plan for implementation. Starting Wednesday afternoon, the second half of the workshop is led by high school teachers who have implemented active learning engineering projects successfully with their own students. A formal presentation of example projects, standards for evaluation and the importance of public presentations are followed the next day by a visit from several high school students. Care is taken to select students with varying abilities, since it is sometimes hard for attendees to believe that methodologies originally developed for gifted HMC freshmen will be successful with a wide range of high school students.

The attendees form groups for this part of the workshop themselves. The teaching team suggests that teachers in the same discipline might produce activity ideas together, or teachers from the same school might work on interdisciplinary projects. Some topics that must be addressed as they formulate assignments are:

- Which parts of the engineering design process fit well into the curriculum of the class?

- How can active learning exercises cover subjects required by restrictive curriculum standards?

- What is the duration of the project?

- How much time will students spend on the project, both in and out of class? 
- What materials should be provided by the teacher, what resources might the teacher use to acquire these resources?

- What documentation should be required of students?

- How can interaction of students with their communities be increased by these projects?

The PEPS organizers feel that it is important that all projects include careful self-planning and scheduling by students, hands-on construction of prototypes, final presentations (to a public audience if possible), and grading via both instructor and peer evaluations. One high school teacher has found that inviting outside observers to evaluate the presentations serves to motivate the students to hold themselves to higher standards. This is also an avenue for increased involvement of other members of the community in the work of high school students.

Some of the projects proposed in 2001 are:

- Design and select strategies to maximize the height reached by a bottle rocket (including a means of measuring the height realized)

- Design and construct a model of a physiological system

- Design a means of testing for the presence of gold

- Design a track system to launch objects into a known/predicted trajectory, or for as long a trajectory as possible

- Participation in a industry sponsored national competition to research and describe radical new technologies

Of course, it is also important that the high school students be made aware that the methodology they are using is an engineering design process. In addition to increasing student interest in SMT in general, the PEPS organizers hope that these projects introduce the possibility of engineering as a career to the students who take part in them. To this end, during the second half of the workshop other interactive engineering tools that might excite high school students are presented. For example, in 2001 participants were introduced to the West Point Bridge Designer contest [4].

\section{Women in Engineering and Science}

Since almost all of the attendees have a majority of students who come from groups underrepresented in science and engineering, a discussion of ways to encourage these students to pursue these fields beyond high school is an important component of PEPS. In 2001, with the introduction of a significant number of attendees from girls' schools, a focused discussion on women in technical fields was held. In this initial conversation, attendee experiences determined the topics to be discussed. In future workshops, however, more structured content will be added, and the time allotted for the discussion will be increased so that issues specific to minority students may be discussed as well. Also, following the suggestion of a participant, the task of designing a strategy for increasing the interest of girls and minorities in SMT might be posed as a brief design exercise for the attendees. 


\section{Assessment of PEPS}

An important element of the ongoing changes to and success of PEPS is the commitment of the teaching team to a formal process for assessment. Each workshop participant is asked to complete an assessment survey at the end of the workshop, and the results are carefully examined by the teaching team. When appropriate, changes in the content or the structure of the workshop are made if it appears that specific goals are not being realized.

The assessment instrument was developed by Karen Yoshino, Executive Assistant to the HMC President for Institutional Research and Assessment. Dr. Yoshino worked with Dr. Christine Cunningham of the Ithaca Evaluation Group to develop the first version of the assessment instrument. They also oversaw the initial use of the survey during the first PEPS workshop and tabulated the results. The key focus was on whether or not the participants believed that the goals of the workshop were likely to be achieved by the current approach and structure. The teachers were specifically cautioned that the assessment instrument was not intended to be used to evaluate the teaching team. If they felt that the teaching team had done particularly well or poorly, they should communicate that to the assessment team in a separate communication.

The first survey revealed that the attendees did not feel that they had sufficient time to digest the engineering methods, that the workshop was too short, and that implementation at their own schools was, in many cases, unlikely unless they could take away specific lesson plans. As a result, the workshop was extended to a fourth day the following year, and the responsibilities of the high school teachers on the teaching team were increased. In addition, the attendees expressed some concern that PEPS goals with respect to underrepresented groups in engineering were not being addressed in a sufficiently direct way. The teaching team has wrestled with this question for some time and is continuing to do so. Changes made in response to the early assessment surveys include increasing the percent of attendees from schools with underrepresented populations, selecting a particular target population (women in 2001), and adding workshop discussion sessions to allow teachers to share ideas and suggestions with one another.

The survey instrument has been repeated each year with only minor modifications. The content of the current survey instrument is presented in Figure 3. Results from the most recent workshop, organized in terms of the specific goals the workshop seeks to accomplish, are:

Goal: Increase teacher skills and tools The survey found that 25 of 26 respondents (96\%) agree or strongly agree that the workshop had provided them with new skills and tools they can use in teaching. Average levels of confidence in the topical areas were in the 4.2 to 4.4 (1=low, $5=$ high) range with the exception of two topics. One of the two areas, defining metrics (3.2) provides an interesting check on the integrity of the survey. Defining metrics was not explicitly covered in the workshop (but was in the printed materials). As expected, this scored the lowest in terms of confidence and knowledge by the participants. 23 of 26 respondents (88\%) agree or strongly agree that the workshop gave them language to bring to students about the work of engineers. A typical comment was, "Now I have a true understanding of what engineers do and look forward to imparting to my students some of the excitement and "fun" that the engineering problem-solving process engenders." 
Figure 3: Harvey Mudd College PEPS Workshop assessment survey. On the actual form, space is provided for comments following each question.

Please respond to the following questions by either placing an " $x$," or number (as requested) by the description that most closely reflects your reaction. Please feel free to expand your responses in the "comments" spaces provided.

\section{Goal: Increase teacher skills and tools}

This workshop has provided me with new skills and tools I can use in teaching my students. strongly agree _ agree __ neutral __ disagree __ strongly disagree

On a scale of 1 to 5 , with five being the strongest, I feel confident about my knowledge in the following topics: refining problem statements establishing functions defining metrics generating alternatives clarifying objectives and constraints weighted objective analysis building prototypes external review board

This workshop was instrumental in giving me language to bring to students about the work of engineers and design. strongly agree agree neutral disagree strongly disagree

\section{Goal: Increase learning opportunities and skills for students}

The techniques covered in this workshop will be appealing to my students. strongly agree agree neutral disagree strongly disagree

The techniques covered in this workshop will contribute to the critical thinking skills of my students. strongly agree agree neutral disagree strongly disagree

I plan to incorporate the following into my teaching plan: refining problem statements defining metrics generating alternatives clarifying objectives and constraints establishing functions weighted objective analysis building prototypes external review board

The methods students learn through practicing workshop methods have the potential of encouraging students who might never have thought about pursuing engineering education to do so. strongly agree agree neutral disagree strongly disagree

\section{Goal: Improve quality of science, math, and technology education environment}

The approximate number of students who will be instructed in these methods by me in an academic year is

The approximate number of underrepresented minorities and females who will receive this instruction in an academic year is

The methods in this workshop are useful in integrating engineering into science and math education at the high school level. strongly agree agree neutral disagree strongy disagree

The discussion on girls and women's issues was useful and informative. strongly agree agree neutral disagree strongly disagree

Please write any other comments about the workshop, the contents, suggestions for improving, etc. you think we need to know. 
Goal: Increase learning opportunities and skills for students The survey instrument found that 23 of 26 respondents (88\%) agree or strongly agree that the workshop will be appealing to their students, and 25 of $26(96 \%)$ agree or strongly agree that the techniques covered will contribute to student critical thinking skills. Of the specific design topics and techniques covered in the workshop, 21 of the 26 respondents expect to include each of the topics except metrics (not covered in the workshop), and external review boards (which is essentially an administrative issue). Finally, 23 of 26 respondents (88\%) agree or strongly agree that the methods taught in the workshop will encourage students to consider engineering who would not have done so otherwise. A typical comment was, "They will love the hands-on nature of the design process." Some teachers did draw a distinction between the engineering aspects (i.e., the vocabulary of engineering design) and critical thinking/problem solving. For example, "This is a great path to teaching critical thinking," and "What you refer to as the engineering design process is really a thought process that is applicable to almost all real life problems in all fields of endeavor."

Goal: Improve quality of science, math and technology education environment The motivation for directing the workshop toward teachers rather than students is the greater number of students ultimately to be affected, and the manner in which they will be influenced. The above goals address the second of these. This year's attendees predict that they will teach 2515 students through PEPS-type projects in the 2001-2002 academic year. Of these, 76\% are either underrepresented minorities or females or both. This high percentage is, of course, in large part a consequence of the targeting of girls high schools. Several teachers from largely minority schools commented that the approach should allow them to introduce engineering into an environment where there are few engineers as role models.

Finally, the discussion of girls and women's issues found the highest level of disparity in responses. 17 of 25 respondents (68\%) agreed or strongly agreed that the discussion was useful and informative, 6 respondents were neutral (24\%), and 2 respondents disagreed (8\%). The comments on this question covered a wide range of responses, ranging from a desire for more time and discussion on this topic to one respondent who asserted this topic has been covered "ad nauseum." Several respondents suggested that separate minority and female discussions be held. Of all the questions on the assessment form, this one probably requires the most attention to the nuances of the comments. A close reading of the responses strongly suggests that the participants are seeking specific strategies for encouraging girls to study engineering and the sciences, and that the workshop did not adequately answer this need. It is the hope of the teaching team that active learning with engineering design projects can be a useful tool for such encouragement.

In the future, the team is committed to additional surveys of participants to determine whether or not the lesson plans developed were implemented, and the teachers' experiences in doing so. The specific plan for this is still at the discussion stage. 


\section{Effect of PEPS on HMC Engineering Education}

One of the unintended but beneficial consequences of the summer workshop has been the opportunity for interactions between PEPS and HMC's E4 course. Because both presume no prior exposure to engineering or design, and both are project-based, the temptation to use PEPS as a "sounding board" for pedagogical experiments has been irresistible. Use of a completely lecture-free approach as part of the studio experience, for example, was first attempted at PEPS. Studio methods are now the standard approach used to teach design at HMC.

Similarly, because the teachers who participate in PEPS are so willing to express their views and opinions, HMC professors have been able to use the workshop as a testing ground for experiences and exercises. For example, one issue of great concern to faculty who teach engineering in studio mode is to determine what sorts of things increase or inhibit students' sense of control over their environment and their activities. As previously described, one of the empowerment experiments tried at PEPS was to simply place all the furniture in the center of the studio and have the teams organize their own workspaces. This simple activity has been found to make students much more willing to take command of the activities within the studio and is now used in E4.

A similar finding from PEPS that has affected HMC's plans for a future studio space was the observation that changing from square tables to round ones seemed to increase the level of cooperation among team members. (The tables were randomly provided by HMC's facilities group.) This has led several HMC faculty members to begin what will eventually be a study of the role of physical spaces on learning by engineering students.

Finally, HMC faculty have had the opportunity to learn from the non-college members of the teaching team and from the participants themselves. Probably the best example of this is in the area of requiring research by engineering students. Because HMC students are generally very talented, they often fail to see the need to consider prior work on a problem. As previously noted, a research requirement developed by one of the high school teachers has been incorporated into PEPS and E4 assignments to insure that all students have learned to use an academic library and the associated research tools.

\section{Conclusions and Future Directions}

At this point, the PEPS program has achieved what might be considered a reasonable level of curricular stability. The basic structure of the workshop is established, the teaching team understands and appreciates both the engineering and K-12 issues that the workshop addresses, and the team is confident that the approach is generating positive outcomes for the teachers and (hopefully) students. HMC intends to continue PEPS into the foreseeable future, making adjustments in response to assessment results and the natural inventiveness of the teaching team.

The curriculum for the PEPS workshop in 2002 will be similar to that for 2001. The most significant change will be more explicit emphasis on methods to encourage participants' students, all of whom come from underrepresented groups, to pursue engineering and science. In 2002 there will still be a special focus on bringing technical opportunities to girls; the goal is to 
have at least half of the participants come from girls' schools. In the long term, the teaching team plans to focus for several years in a row on different underrepresented groups.

Expansion of the teaching team will occur in several directions. In addition to at least one more HMC faculty member, the team will be joined by one or two attendees from last year. These will be from schools outside California, and the hope is that by 2003 there will be a satellite PEPS workshop run by HMC faculty and the new high school teaching staff at a location elsewhere in the country. In order to further increase opportunities for expansion, a faculty member from Smith College's Engineering Science program has also been invited to join the teaching team in 2002. Besides increasing the ability of PEPS to reach teachers of girls, inclusion of Smith faculty might also be an avenue for starting a satellite workshop.

\section{Acknowledgements}

The authors would like to acknowledge the other members of past and present PEPS teaching teams, particularly Jim Rosenberg from HMC, Ann Dell from the Oklahoma School of Science and Math, and Mary Lee Davis from Brea Olinda High School. The work by the Dartmouth PEPS program (especially Carol Muller) in initiating and supporting the HMC program are also especially noteworthy. The support and assistance of the HMC Engineering Department and Development Office are greatly appreciated.

\section{References}

[1] Dym, Clive, "Teaching Design to Freshmen: Style and Content", Journal of Engineering Education, Vol. 88, no. 2, 1999, pp. 189-194.

[2] Little, Patrick and Mary Cardenas, "Use of "Studio" Methods in the Introductory Engineering Design Curriculum", Journal of Engineering Education, Vol. 90, no. 3, 2001, pp. 309-318.

[3] Dym, Clive and Patrick Little, Engineering Design - A Project Based Introduction, John Wiley and Sons, 2000.

[4] United States Military Academy, "The West Point Bicentennial Engineering Design Contest," 2001. Accessed 1/11/02. http://bridgecontest.usma.edu.

LORI BASSMAN is an Assistant Professor of Engineering at Harvey Mudd College. She received a B.S.E. in Mechanical and Aerospace Engineering from Princeton University and a M.S. and Ph.D. in Mechanical Engineering from Stanford University. Her research is in the field of computational mechanics, with an emphasis on modeling coupled physical phenomena in the thin-film metals that comprise microelectronic interconnects.

PATRICK LITTLE is the J. Stanley and Mary Wig Johnson Associate Professor of Engineering Management at Harvey Mudd College. He received a B.A. in Philosophy from St. John's University, and a S.M. in Transportation and Sc.D. in Civil Engineering from the Massachusetts Institute of Technology. His research interests are generally focused on the design and management of engineered systems, particularly railroad systems. 